\title{
Methodological Approaches to End-Of-Life Modelling in Life Cycle Assessments of Lithium-Ion Batteries
}

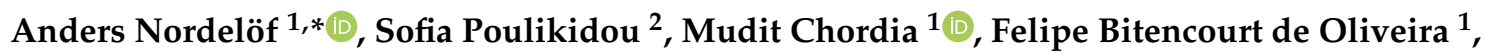 \\ Johan Tivander ${ }^{1}\left[{ }^{1}\right.$ and Rickard Arvidsson ${ }^{1}$ \\ 1 Environmental Systems Analysis, Chalmers University of Technology, SE 41296 Gothenburg, Sweden \\ 2 Mechanics and Maritime Sciences, Chalmers University of Technology, SE 41296 Gothenburg, Sweden \\ * Correspondence: anders.nordelof@chalmers.se; Tel.: +46-317728611
}

Received: 12 April 2019; Accepted: 24 June 2019; Published: 2 July 2019

\begin{abstract}
This study presents a review of how the end-of-life (EOL) stage is modelled in life cycle assessment (LCA) studies of lithium-ion batteries (LIBs). Twenty-five peer-reviewed journal and conference papers that consider the whole LIB life cycle and describe their EOL modelling approach sufficiently were analyzed. The studies were categorized based on two archetypal EOL modelling approaches in LCA: The cutoff (no material recovery, possibly secondary material input) and EOL recycling (material recovery, only primary material input) approaches. It was found that 19 of the studies followed the EOL recycling approach and 6 the cutoff approach. In addition, almost a third of the studies deviated from the expected setup of the two methods by including both material recovery and secondary material input. Such hybrid approaches may lead to double counting of recycling benefits by both including secondary input (as in the cutoff approach) and substituting primary materials (as in the EOL recycling approach). If the archetypal EOL modelling approaches are not followed, it is imperative that the modelling choices are well-documented and motivated to avoid double counting that leads to over- or underestimations of the environmental impacts of LIBs. Also, 21 studies model hydrometallurgical treatment, and 17 completely omit waste collection.
\end{abstract}

Keywords: life cycle assessment; lithium-ion; battery; end-of-life; recycling; cutoff

\section{Introduction}

Lithium-ion batteries (LIBs) have been widely used as power and energy storage components in consumer electronics and portable devices, such as mobile phones and laptops, since the 1990s [1]. Compared to other commercially available battery types, LIBs offer, for example, high energy density, long calendar and cycle lives, as well as high energy efficiency [2]. Rapid adoption of LIBs in a range of applications within the energy and transport sectors has placed them at the core of several emerging and growing technologies addressing energy security, climate change, and fossil fuel dependency. For the development of electromobility, and road-bound electric vehicles in particular, LIBs have grown to become the dominant battery technology [2-4]. In the wake of the LIB technology success, there are environmental and resource challenges. With global demand almost doubling every five years, concerns about material availability have been raised, especially for lithium and cobalt [2,4-8]. In addition, earlier research points towards high energy intensity in battery manufacturing, albeit with significant variability between studies, which offsets some of the environmental benefits associated with LIB utilization [9-11]. For this reason, it has been suggested that the use of recycled battery materials can reduce energy use and emissions associated with LIB production [12,13], and that battery recycling is a good way to ensure future availability of battery raw materials $[2,5,14,15]$. 
As a response, a number of life cycle assessment (LCA) studies have been carried out with the aim to uncover the environmental impacts of LIBs [9-11,16,17]. LCA is as a well-established tool used for analyzing the environmental impacts of products, services, and technologies. In LCA, a life-cycle perspective is employed, and different stages can be identified: Raw material acquisition, production, use and end-of-life (EOL). In the final stage, batteries are scrapped, and go to waste treatment and possible recovery of materials. However, different case study results vary notably, and earlier literature reviews of the research field, covering traction batteries in general or LIBs in particular, relate those variations to methodological choices, such as the modelling approaches, system boundaries, and data sources, including inconsistencies [9-11,16]. Among these reviews, only Ellingsen et al. [9] discuss the EOL stage, albeit briefly. The discussion includes summarizing the technical scope of the EOL stage for each study and mentioning the main modelling approaches [9], but no in-depth analysis. However, lack of methodological awareness and rigor in EOL modelling may constitute a risk for under- or overestimating the benefits of battery recycling. There are also clear examples of differing results for the EOL of LIBs. For example, Li et al. [18] report that the EOL stage stands for 3\% of the overall LIB contribution to climate change and over $28 \%$ in the case of ozone depletion impact. In contrast, Sanéflix et al. [19] report that recycling of LIBs can reduce the life-cycle climate change impact by approximately one quarter.

Considering the expectation that recycling will reduce both production emissions and the need for primary raw materials, together with significant and notably different life-cycle impacts reported for recycling of LIBs, it can be concluded that little attention has been given to EOL modelling approaches applied in LCAs of LIBs. To address this gap, the purpose of this paper is to review the modelling approaches used for the EOL stage in peer-reviewed LCA studies of LIBs. The focus is to investigate methodological consistency (and inconsistency) and to discuss qualitatively how EOL modelling influence results, by giving examples. Additional aims are to complement previous review work in the research field, assist interpretation of existing studies and support the EOL modelling in future LCA studies of LIBs. Before presenting the review procedure (Section 4) and the findings (Section 5), we provide a brief description of relevant treatment and material recovery processes for spent LIBs (Section 2), as well as a description of standard approaches for modelling the EOL stage according to generic LCA methodology (Section 3). At the end, results are summarized into main findings (Section 6).

\section{Technical Background}

LIBs consist of battery cells containing an electrolyte, a separator, a cathode, and an anode [2,20]. Various types of LIBs are available, denoted after the active cathode material, including lithium iron phosphate (LFP), lithium cobalt oxide (LCO), lithium manganese oxide (LMO), nickel cobalt aluminum oxide (NCA), and lithium nickel manganese cobalt oxide (NMC) [2]. Each of these active materials results in different battery properties and characteristics, making them suitable for different applications. The cathode also includes an aluminum current collector adjoining the active material. For the anode, the dominant design is graphite attached to a copper current collector, and for electrolyte materials, a lithium salt is mixed with organic solvents [2,3]. The separator, which serve as an electrical isolation between the two electrodes to prevent short circuits, is commonly made of polyethylene or polypropylene [2]. For larger applications, cells are often combined into packs, which provides structural elements, cooling equipment, internal conductors and wiring, external connectors, sensors, control electronics, and a protective enclosure $[17,21,22]$. Typically, the materials dominating in these other pack components are aluminum, steel, or copper $[17,21,22]$. Although the technologies and networks required for effective EOL handling of LIBs are still evolving $[13,14]$, several schemes have been developed for recovering various materials [23]. 


\subsection{Waste Treatment of LIBs}

The first step in the EOL of batteries, as for any product, is waste collection. A high collection rate is a key to effective recycling, but its realization can be a challenge. Annual national statistical waste collection data is usually based on what is placed on the market compared to what reaches the waste handling facilities the same year [24]. Such data for LIBs in the EU shows that the total battery waste collection rates currently are low ( $0-25 \%$ in different countries). However, for products with growing production volumes, such as LIBs, the average product's life must pass before the waste collection volumes are able to catch up, meaning that current data is likely not representative for the future EOL collection rate. Another explanation for low collection rates is that smaller LIBs are often embedded in products such as laptops, where they end up in unreported channels for trade and recycling, e.g., in China and South Korea [24,25]. In addition, for other small LIBs used in portable electronic devices, mobile phones and laptops, there is also a significant hibernating stock in society [24]. Still, battery waste collection constitutes a challenge both in the real world as well as in terms of LCA data availability. In contrast, for well-established product systems, such as steel and aluminum metal, representative average collection data is available.

Nevertheless, for collected batteries, a number of pretreatment steps typically follows, with the aim to separate waste streams that later may take different routes in the EOL processing [14,26,27]. Pretreatment often includes dismantling, sorting and shredding $[23,26]$. The latter means that a large mill crushes the component into several material fractions, which are sorted automatically [28]. LIB packs and cells are thus disaggregated into different residues: electronics, plastics, containers, current collectors and conductors, anode materials, and cathode materials. Some of these material streams are subject to further waste treatment (e.g., incineration or landfilling), whereas others undergo material recovery.

\subsection{Material Recovery from LIBs}

For material recovery from LIBs, chemical processes and "direct recycling" procedures are available $[23,26,27,29]$. The chemical metal extraction methods can be divided into two main types: Pyrometallurgical and hydrometallurgical treatment. Pyrometallurgical schemes, employing pyrolysis, were initially the most common for industrial recycling of spent LIBs [23]. Dismantled modules or shredded batteries are smelted in a furnace along with limestone as a slag-forming agent. Plastics and solvents burn to provide energy for a reaction where valuable metals such as nickel, cobalt, and copper form a relatively pure alloy [23,29]. However, other metals, including lithium, aluminum, and manganese end up in the slag, making them much more challenging and costlier to recover. Hydrometallurgical schemes often involve acid leaching of metals from battery residues, which are then separated and recovered as pure metals or metal salts by solvent extraction, precipitation, or electroextraction $[27,30]$. A benefit of hydrometallurgy is that almost any material can be recovered, but drawbacks include needs for large quantities of hot water, acids, and solvents [23].

Direct recycling is a material recovery process where the cell constituents are detached without altering their chemical form, allowing direct reuse in battery production, or requiring only minor refurbishment $[29,31]$. Following disassembly and breaching, cells are treated in chamber with fluid carbon dioxide, after which the electrolyte is extracted for reuse and the remaining materials are pulverized and separated. This method enables most materials of the cell to be recycled, although minor upgrading can be required $[23,29,31]$.

\section{EOL Modelling Approaches in LCA}

Several approaches have been suggested for the modelling of EOL in LCA [32,33]. However, in practice, there are currently two main methods being used: The cutoff approach (also called the "recycled content approach") and the EOL recycling approach (also called the "avoided burden 
approach") [34,35]. Note that waste treatment, at least in the form of collection, is a step in the EOL modelling that is generally included in both approaches.

\subsection{Cutoff and EOL Recycling}

In the cutoff approach, the fates of recyclable materials are not modelled all the way to where they recirculate into new production. Instead, commonly only collection and the steps referred to as pretreatment in the battery recycling literature (see Section 2) are included. In the typical setup, this means that the recovery and upgrading of recyclable materials are "cut off" from the product system, and that no credits are awarded for providing waste streams containing materials that are recycled back to the same or other product systems, i.e., as secondary raw materials. Instead, benefits are given in the upstream modelling of input raw materials, when a certain share $(x)$ of input for a specific material is assumed to consist of secondary input, while the remainder $(1-x)$ comes from primary material extraction. The input of secondary raw materials is charged only with the burdens caused by the recovery and upgrading processes. In total, this implies an overall reduced production impact for products with recycled content, and the assumed share $\mathrm{x} 1, \mathrm{x} 2$, etc. of different secondary materials are key parameters in this approach. Note also that the recycled content does not need to match the recyclable output from the product system, since it could just as well originate from material recovery of some other product. The cutoff approach is illustrated graphically in alternative (a) of Figure 1.

(a.)

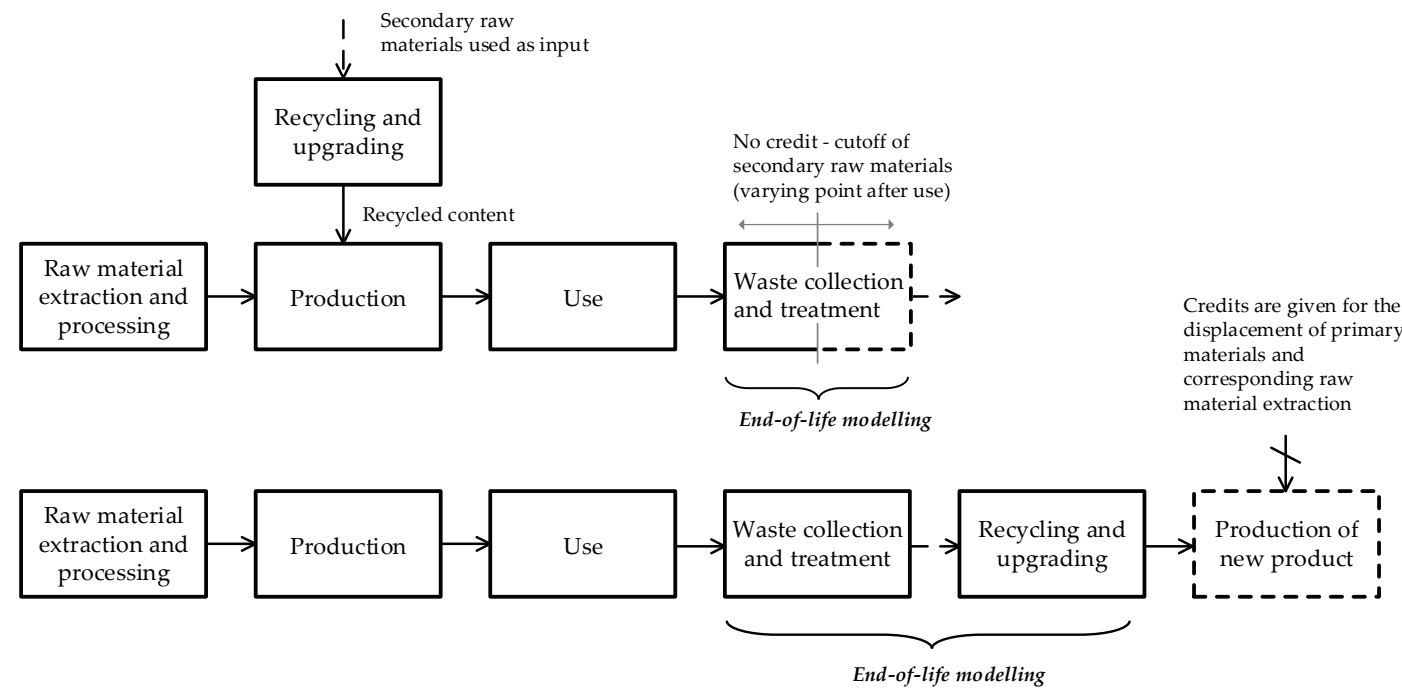

Figure 1. Illustration of (a) the cutoff approach, and (b) the end-of-life recycling approach. Boxes show processes, full arrows show material flows, broken arrows show scrap material flows, and crossed arrows show substituted material flows. In alternative (a), the position of the cutoff point may vary, and as a result, the scope of upstream "recycling and upgrading" varies correspondingly. Although not shown, upgrading generally requires some blending with primary materials.

There are different opinions in the LCA research field on where to set the cutoff point. Suggestions include directly when the use phase has ceased, or after collection and transportation to a scrapyard, supposedly when the value of the scrap is the lowest $[35,36]$. However, many used products contain both recyclable and non-recyclable materials, where the latter proceed to further treatment such as incineration or disposal in a landfill. If such waste treatment is required, it is always attributed to the product under study [33], and for this reason it is common to model the cutoff point after sufficient separation and sorting to make a clear distinction between the flows recirculating into a new product life cycles, and remaining waste flows. In agreement with this setup, waste treatment processes included in cutoff system model of the Ecoinvent database place the cutoff point after separation and sorting, for example after vehicle shredding [37]. For LIBs, a similar scheme would include pretreatment, and then make the cutoff before materials are restored by subsequent recovery processes. 
Importantly, to be consistent, the EOL cutoff should be made at a point which harmonizes with the input data used for the secondary raw materials in the production stage.

In the EOL recycling approach, shown as alternative (b) in Figure 1, the material recovery is explicitly modelled instead of being cut off. In particular, the recovered quantity of a material is typically assumed to directly replace an equivalent amount of primary material upstream in the product system, or in a different product system. In essence, this recycling reduces the need for primary material production and the environmental burdens linked to the use of a corresponding amount of primary material can be avoided. Hence, these avoided impacts are credited to the product studied in the EOL stage as negative impacts. A key feature of this approach is that, regardless of any actual recycled content in products in the real world, if the EOL crediting is based on avoided primary material production, then all of the material input upstream in the LCA model also should bear the load of primary metal production [35]. Otherwise, benefits of recycling are accounted for twice in the same life cycle.

\subsection{Closed-Loop, Open-Loop and Closed-Loop Approximation}

Another way to categorize EOL modelling is to specify whether the recycling occurs in a closed or an open loop [38]. In closed-loop recycling, recovered material is recirculated back to the same product system, i.e., the same production (or type of production) that made the product from which the material was recovered [38]. An example could be lithium from a scrapped LIB, which is recycled into a LIB of the same type. In alternative (a) of Figure 1, this would occur if the broken arrow representing scrap going out of waste treatment is connected back upstream directly to the other broken arrow entering the recycling and upgrading process. In such a case, only net raw materials need to be accounted for. However, even though promising methods are emerging for such "functional recycling" back to original use for many LIB battery materials, the current situation in many large-scale recycling systems is very different. For example, in real EOL for vehicles, closed-loop recycling is non-existent for most materials [28].

In open-loop recycling, the recycled material is instead used in a different product, an example being the use of cobalt from recycled LIBs in samarium-cobalt magnets for sensors and electric motors. However, since large scale waste treatment, e.g., shredding, often involves some degree of material intermixing and dispersion of metals present in small quantities into recovered bulk metals, such as steel and aluminum, open-loop recycling is typically not functional [28]. Instead, materials have lower quality and are down-cycled into products with lower material quality requirements. To compensate the lower quality, secondary and primary materials are commonly mixed in varying shares to match material requirements for different applications [39]. In LCA modelling, open-loop recycling has for long been regarded as a challenge, since the environmental burden of the initial material production, the waste treatment and the material recovery can be allocated in many different ways between two or more cascaded product systems [40]. A number of allocation procedures have been suggested to solve this issue for open-loop recycling, with the cutoff approach described above being the simplest to apply and traditionally the most common $[32,33,40]$. Whereas the cutoff approach always pairs with open-loop recycling, since the recycled material feeds into the larger market for recycled materials rather than going directly back to the production, the EOL recycling approach can be modelled both as the closed- or open-loop type depending on type of LCA and the argument for displacement.

There is sometimes a distinction made between attributional, accounting type of LCA and consequential, change-oriented type of LCA. In brief, attributional LCA quantifies life cycle impacts attributable to a product in an established status-quo system, whereas a consequential LCA quantifies changes in life cycle impacts due to a certain decision [41]. The cutoff approach, which is based on fixed average market data for recycled contents, may thus be particularly suitable for attributional LCA. In contrast, the EOL recycling method builds on avoiding burdens by substituting (i.e., changing the demand for) primary materials, and it is the preferred way of accounting for byproducts in consequential LCA [33,42]. The use of substitution in attributional LCA is disputed in the LCA research 
field because it alters the otherwise status-quo system assumed in attributional LCA [42-44]. One reason is that the dynamics of substitution depends on the market situation for the specific material [44]. However, there are arguments for using the EOL recycling approach also in attributional LCA to model open-loop situations, especially if the recovered material has not been subject to any changes of inherent properties and quality, i.e., the recycling is argued to create functionally equivalent materials, because then it can be approximated as occurring in a closed loop [38,40]. Another typical assumption when using such a closed-loop approximation for EOL modelling is that the recovered materials in the studied product system do not displace recycled materials from other products [40] (i.e., not affecting the secondary material market), since the point of the approximation is to circumvent the open-loop allocation problem [38].

\section{Method}

The collection of appropriate articles for the analysis started with a literature search using the Scopus [45] and Web of Science [46] databases, specified for the stated time frame and based on the following search string: ("life cycle assessment" OR "life cycle analysis") AND ("lithium ion battery" OR "lithium ion batteries") AND ("recycling" OR "end of life"). First, LCA case studies of LIBs were identified and selected. Other work was excluded, such as material or substance flow analyses of LIBs, case studies of other battery types, as well as review articles and other overviewing LCA literature. Publications not clearly stated to have been peer-reviewed were also excluded. Next, studies not including the full life cycle from cradle-to-grave, i.e., assessments of LIB production or the EOL stage only, were removed from the collection. This omission was done because the raw material input can otherwise not be put into context with waste treatment practices and material recovery procedures, which is important since batteries can both contain recycled materials and be a source of recovered materials. At this stage, 29 articles remained, and they were all read with special attention to the description of the scope and modelling approach in the method description, the reported inventory data use and impact assessment results for the EOL stage. To complete the review, it was necessary to find at least some information about the EOL modelling. Three studies [47-49], although covering the full life cycle of the battery, do not provide this, and one study [50] directs the reader to another article without any further description. It was therefore decided to exclude these four studies from the review.

As a result, the review includes 25 peer-reviewed scientific journal and conference articles which assess the cradle-to-grave environmental impacts of LIBs using LCA, published from January 2010 until February 2019. All studies include at least one LIB among the technology options, on cell or pack level, or put the LIB into focus as a part of a larger technical system (typically an electrical vehicle product system). The studies were sorted into two main groups representing the two main EOL modelling approaches outlined in Section 3: Those employing the EOL recycling approach and those employing the cutoff approach. Unless explicitly reported, this was done by going through the processes modelled in the EOL stage, classifying those that only included pretreatment processes or less as "cutoff", and those that also included material recovery in the form of pyrometallurgy, hydrometallurgy, direct recycling or other technical methods as "EOL recycling". The inventory data description was checked for recycled content in the material inputs to production, including references to the GREET model [51] and the Ecoinvent database [37]. In addition, the method section and impact assessment results were scanned for reporting of avoided burden and crediting as negative impacts, typical for the EOL recycling.

\section{Results and Discussion}

\subsection{Cutoff, EOL Recycling and Hybrid Approaches}

Table 1 presents a summary of the review results. It shows that 19 of the 25 studies use the EOL recycling approach and 6 the cutoff approach. Among the studies, 15 were marked for closed-loop approximation, including both Sanfélix et al. [19] and Sanfélix et al. [52], who argue for substitution in 
their attributional study setup. In contrast, only one consequential LCA study by Vandepaer et al. [53] was found, where the avoided burden is looked upon as substitution in an open loop scheme.

Table 1. Summary of the peer-reviewed articles included in this review, sorted into "EOL recycling" or "cutoff" for the EOL modelling approach, "primary only" or "recycled content" for the production of raw materials, and "avoided burden" or "no crediting" for the EOL crediting. Materials having a recycled content are stated in parenthesis when reported in the study. The final two rows show (in bold) the expected study setups in order to be consistent with the two main EOL modelling approach as described in Section 3.

\begin{tabular}{|c|c|c|c|}
\hline Study & $\begin{array}{l}\text { EOL Modelling } \\
\text { Approach }\end{array}$ & Production of Raw Materials & EOL Crediting \\
\hline Ahmadi et al. [54] & EOL recycling & Recycled content (Al) & No crediting \\
\hline Ciez and Whitacre [55] ${ }^{1,2}$ & EOL recycling & Recycled content $(\mathrm{Fe}, \mathrm{Ni})$ & Avoided burden \\
\hline Cusenza et al. [56] & EOL recycling & Primary only & Avoided burden \\
\hline de Souza et al. [57] & EOL recycling & Primary only & Avoided burden \\
\hline Dunn et al. [21] ${ }^{1}$ & EOL recycling & Recycled content (Al) & Avoided burden \\
\hline Dunn et al. $[58]^{1}$ & EOL recycling & Not reported & Avoided burden \\
\hline Faria et al. [59] & EOL recycling & Not reported & Not reported \\
\hline Gaines et al. [12] & Cutoff & Recycled content & No crediting \\
\hline Hendrickson et al. [60] ${ }^{1}$ & EOL recycling & Not reported & Avoided burden \\
\hline Li et al. $[18]^{2}$ & EOL recycling & Recycled content (Al) & No crediting \\
\hline Notter et al. [61] ${ }^{2}$ & Cutoff & Recycled content (Al) & No crediting \\
\hline Oliveira et al. [62] & Cutoff & Recycled content & No crediting \\
\hline Oliveira et al. [4] & EOL recycling & Not reported & Avoided burden \\
\hline Raugei and Winfield [63] ${ }^{2}$ & EOL recycling & Recycled content $(\mathrm{Al}, \mathrm{Cu})$ & Avoided burden \\
\hline Richa et al. [64] & EOL recycling & Recycled content (Al, Cu, Fe) & Avoided burden \\
\hline Ryan et al. [65] ${ }^{1,3}$ & Cutoff & Recycled content (Al, Fe, Li) & No crediting \\
\hline Sanfélix et al. [19] & EOL recycling & Not reported & Avoided burden \\
\hline Sanfélix et al. [52] & EOL recycling & Not reported & Avoided burden \\
\hline Swart et al. [66] ${ }^{4}$ & EOL recycling & Primary only & Avoided burden \\
\hline Tagliaferri et al. [67] ${ }^{2}$ & EOL recycling & Not reported & Avoided burden \\
\hline Unterreiner et al. [68] ${ }^{5}$ & EOL recycling & Primary only & Avoided burden \\
\hline Vandepaer et al. [69] & Cutoff & Not reported & No crediting \\
\hline Vandepaer et al. [53] ${ }^{2,6}$ & EOL recycling & Not reported & Avoided burden \\
\hline Zackrisson et al. [36] ${ }^{2}$ & Cutoff & Recycled content & No crediting \\
\hline Zhao and You [70] & EOL recycling & Recycled content & No crediting \\
\hline EOL recycling approach & EOL recycling & Primary only & Avoided burden \\
\hline Cutoff approach & Cutoff & Recycled content & No crediting \\
\hline
\end{tabular}

Two studies, Ryan et al. [65] and Swart et al. [66], were found to model closed loops in the foreground system, making their studies challenging to classify as the cutoff and EOL recycling approaches then coincide as one. Especially, Swart et al. [66] is an excellent example of a closed-loop model where only net primary raw materials are considered in terms of inputs to the product system, as described in Section 3. Still, it was sorted among the EOL recycling studies since it includes modelling of the material recovery processes, in line with the principle for sorting the studies as reported in 
Section 4. Nonetheless, also when taking these two studies into account $[65,66]$, this review confirmed the general dominance of the two main EOL modelling approaches (cutoff and EOL recycling) also in peer-reviewed LCAs of batteries, specifically. In fact, no instances of other approaches were found in the literature collection.

In addition to the studies reviewed, Table 1 also includes two rows at the bottom indicating the expected typical setup of the cutoff and EOL recycling approaches, which are in line with the general arguments for using either method as presented in Section 3. It was found that 7 of the reviewed studies are not consistent with these two conventional setups. Consequently, there is a risk of underor overestimation of the environmental benefits of recovering battery materials in these studies, as illustrated in Figure 2. For the EOL recycling approach, Richa et al. [64] constitutes an example of potential double counting (see example 5 in Figure 2), where the upstream raw material input includes recycled content for steel (37\%), aluminum (32\%) and copper (15\%). At the same time, the recovered materials include aluminum and copper, which are credited for avoiding burden corresponding only to primary material production [64,71], without clearly explaining the logic. Similarly, Ciez and Whitacre [55] model avoided energy use and coupled reductions of carbon dioxide emissions brought about by material recovery of copper, iron, nickel, cobalt, and cement slag from pyrometallurgical treatment; lithium, nickel, cobalt, manganese, and iron from hydro-metallurgical treatment; or complete cell canisters, current collectors, and cathode precursor materials from direct recycling. Even so, they also report the use of secondary steel and nickel in the original material production. It is difficult to judge to what extent this implies double counting of benefits from recycling in the same product life cycle, and the degree that environmental and resource impacts of the studied LIBs are underestimated, but it creates uncertainty about the validity of the results.

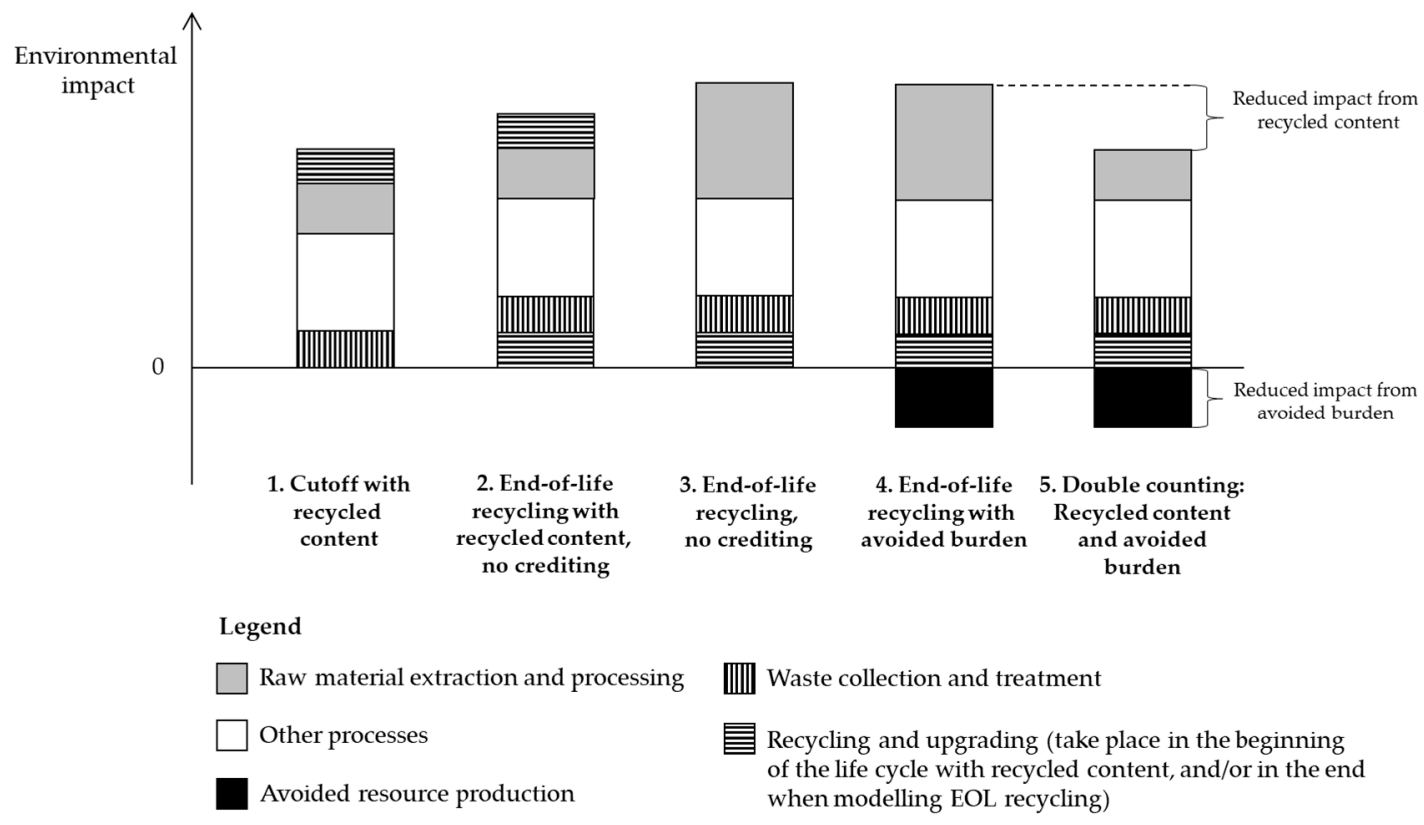

Figure 2. Schematic illustration of how environmental impacts vary depending on the selection of EOL modelling approach, if the study uses the expected setup for cutoff (1) or EOL recycling (4), or apply a hybrid version (2,3, or 5). Using the EOL approach without giving any credits for recycling (2 or 3) leads to a conservative estimation of the environmental and resource impacts of LIBs, whereas modelling both recycled content and avoided burden (5) implies double counting which may underestimate the impact. Bar sizes are indicative only and do not reflect actual results.

In contrast, Ahmadi et al. [54], Li et al. [18], and Zhao and You [70] make conservative estimations for a number of environmental impact categories by taking recycling procedures into account in both ends of the battery life cycle, i.e., including recycled content as well as modelling the material recovery 
processes in the EOL stage, but without giving any credits (see example 2 in Figure 2). At large, this is in line with the cutoff approach, but it violates the convention of setting the cutoff point before or at the place where recyclables and non-recyclables are separated, by also including material recovery and upgrading processes in the studied system. The main argument against this violation is that the subsequent product system, which is the driver for the material recovery and upgrading, should carry the environmental impacts of the recovery and upgrading processes, especially if the same principle governs the upstream cutoff point preceding the studied product system. On the other hand, since there are regulations making battery recycling compulsory, for example the EU Battery Directive enforcing at least 50\% recycling by mass for LIBs [72], it can be argued that the life cycle of the product under study should include material recovery even for the cutoff approach. But such detailed discussions about system boundaries for the EOL stage are rarely encountered in the reviewed LCAs of batteries. Thus, it is reasonable to claim that this conservative approach rather overestimates the environmental and resource impacts of LIBs.

Returning to Ryan et al. [65], it can also be observed that hybrid versions of the cutoff and EOL recycling approaches are sometimes purposefully used. In this study, they report having applied the cutoff approach, including waste handling for the EOL stage and recycled content included for the input of aluminum and steel, but also for a lithium salt $\left(\mathrm{Li}_{2} \mathrm{CO}_{3}\right)$. However, since their main data source, the GREET model, does not contain lithium salt as an option for recycled content, they explicitly point out that they modelled a closed loop for the lithium salt and that the burden of those material recovery processes is ascribed to the production stage. Hence, the study was classified as using the cutoff approach and closed-loop recycling at the same time, even though the cutoff generally implies open-loop recycling.

This observation also brings attention to the fact that the default settings of the GREET model include recycled content $[21,55]$, i.e., making it suitable for use in combination with the cutoff approach. Similarly, the often-used Ecoinvent database contains recycled content in average market and production mix datasets for the attributional systems models. In order to use these data sources in combination with the standard setup of the EOL recycling approach, primary raw materials should be selected deliberately. However, such databases are complex and may include aggregated datasets with recycled fractions for multiple materials, e.g., in electronic units in Ecoinvent [37]. This makes them difficult to combine with the EOL recycling approach and its requirement of only primary raw material input. However, the problem of 'hidden' recycled content in market datasets becomes less problematic to use for the EOL recycling approach if the recycled content is minor (e.g., $<10 \%$ ), whereby the dataset still can be seen as a decent proxy for primary material production. Any such approximation should preferably be stated clearly to enable users of the study's results to interpret the model. Carefully applied hybrid approaches, where specific materials are modelled with different approaches, is another possible solution, but it also requires the study to be reported with detailed information about the modelling in order for the reader to interpret results. Ryan et al. [65] do this in a commendable way.

Another option is argued for by Raugei and Winfield [63], namely to calculate the credits using production mix data containing both primary and secondary materials. By doing so, they claim to be consistent even though they combine recycled content with crediting for avoided burdens. However, this implies a break with a common assumption for the closed-loop approximation, which in turn is a key justification for the use of avoided burdens in attributional LCA: The assumption that no secondary materials from other products are displaced. Even though there are supporters for this way of crediting [33], an important objection is that it becomes conceptually difficult to understand the modelling in the open loop context: the studied product system alters the secondary material markets underlying the average production mixes used for the crediting, and thus makes the quantified credit invalid, in a sort of circular reference. In addition, on a more fundamental level, a key purpose of recycling is to decrease the use of natural resources and environmental burden of primary material extraction. This also makes it questionable to replace secondary material with other secondary material. Moreover, in the real world, it is likely that recycling is economically viable mainly when there is a 
demand for recycled materials, and not when different recycled materials are competing [42]. Replacing secondary material with secondary material thus seems unlikely from that perspective too. It thus remains vital to clearly motivate specific modelling choices when disembarking the more established versions of the EOL modelling approaches.

\subsection{Recovery Procedures, Recycled Cell Materials and Waste Collection}

For the technical scope of the cell material recovery procedures, inclusion of pyro- and hydrometallurgical treatment is most common, which is the case in Cusenza et al. [56], where aluminum, cobalt, copper, nickel, manganese, and steel are recovered, and awarded with primary material credits and coupled avoided burden for a broad set of environmental impact categories. Table 2 shows the share of the studies that apply the EOL recycling approach and include the recovery procedures described in Section 2, as well as to what extent they model recovery of the following four elements: cobalt, lithium, manganese and nickel. These metals are typical constituents of cell materials recovered in current real-world industrial practices in China and South Korea [25]. Expectedly, most studies focus on the recovery of cobalt and lithium, which have received attention regarding their future resource availability. In addition, Table 2 displays that schemes based on hydrometallurgy are commonly modelled, and this too is in agreement with ongoing activities in East Asia [25]. Aluminum, copper, and steel belong to the metals which can be recovered from battery cells, but even more so from the casings, conductors and electronics of the entire battery pack, which is separated mechanically from the cells during pretreatment.

Table 2. Summarized results for the number of studies accounting for waste collection of LIBs (relevant for all 25 studies) and modelling specific procedures and materials in the recovery of LIB cells (relevant for the 19 studies modelling the EOL recycling approach).

\begin{tabular}{lc}
\hline \multicolumn{2}{c}{ No. of Studies Accounting for Waste Collection } \\
\hline Include or discuss collection rate & 2 \\
Model the transportation required for collection & 6 \\
Report no aspects of waste collection & 17 \\
\hline No. of Studies Modelling Specific Cell Material Recovery Procedures in the EOL Recycling Approach \\
\hline Direct recycling & 4 \\
Hydrometallurgy & 16 \\
Pyrometallurgy & 12 \\
Other procedures ${ }^{1}$ & 2 \\
\hline
\end{tabular}

\begin{tabular}{lc}
\hline \multicolumn{1}{c}{ No. of Studies Modelling Recovery of Specific Cell Materials in the EOL Recycling Approach } \\
\hline Cobalt & 11 \\
Lithium & 12 \\
Manganese & 6 \\
Nickel & 7 \\
\hline
\end{tabular}

${ }^{1}$ This includes procedures not described in Section 2, for example "intermediate" recycling where lithium salt is recovered from a liquid stream which is diverted during the post-shredder sorting process.

Table 2 also presents the share of all reviewed studies taking waste collection into account, by including losses in the collection step and the transports required. Notably, very few studies include or even discuss the collection rate, i.e., do not acknowledge that a significant number of batteries may never reach dedicated battery EOL handling. A key explanation is that there is a knowledge gap around the collection of LIBs, not only in LCA research, but in general [25], as indicated in Section 2. Nevertheless, given the importance of the collection step for the overall impact of recycling, this is clearly a weakness in current EOL modelling. 


\section{Conclusions and Implications for Stakeholders}

This review has shown that the majority of the selected LCA case studies of LIBs apply the EOL recycling approach, while the remaining share apply the cutoff approach. The results of this study thus confirm the dominance of these two methods also in battery LCA studies. In addition, some hybrid approaches exist. For key stakeholders of LIB technology who rely on information from LCA studies for strategic decision support, such as industrial managers and policy makers, our main message is that these two approaches address the EOL stage in fundamentally different ways, which influences both quantitative results and what information the study provides.

LCA practioners focusing on LIBs are recommended to use the EOL recycling approach for evaluating emerging and developing recycling processes for cells, since it allows for a detailed study of these processes themselves. This may explain its dominance among the reviewed studies. The modelled material recovery procedures generally correspond well to current evolving industry practices, except for the collection step where there are gaps in terms of both inclusion in the study scope as well as in data availability. However, it is important to be aware that the use of a closed-loop approximation, employed in some of the attributional LCA studies reviewed, entails little consideration of potential material down-cycling, or that there is no guarantee that a 1:1 replacement of primary material occurs in a market-mediated open-loop recycling procedure [44]. However, down-cycling can be accounted for by including additional upgrading procedures within the EOL system boundaries and lower displacement rates by crediting for avoided burden using a realistic correction factor [43].

In contrast, both LCA practioners and users of LCA study results should be aware that the cutoff approach is typically appropriate to use in well-established waste treatment and material recovery settings, where the material waste streams supply a noticeable share of the recycled content for specific material markets, typical examples being the common battery pack materials aluminum and steel. Corresponding average market data with appropriate recycled contents is often available in LCA databases, while they usually do not include all new and unexplored material recovery processes. In the conducted review, the cutoff approach was found to be more common among earlier studies, where less was known about potential future recycling processes, or where the EOL stage was in less focus.

As a general observation, inconsistencies compared to the archetypal cutoff and EOL recycling approaches occur when two methods are blended in hybrid versions. Crediting for avoided burden by replacing primary materials in combination with recycled content brings the risk of under-estimating the environmental burden of LIBs. Contrary, giving no credits and at the same time include all material recovery and upgrading instead brings the risk of overestimating burden. Consequently, LCA practioners are recommended to be cautious with such blending. Still, depending on the data available for modelling the production stages, a hybrid approach can sometimes be motivated. But in such cases, when the expected setups of the two archetypal approaches are not followed, it is vital that the modelling choices are well-documented and clearly motivated in order for the target audience of the study to be able to interpret the results. As receivers of LCA results, industrial managers and policy makers are recommended to carefully scrutinize methodological explanations, since they may otherwise receive incorrect decision support regarding the environmental impacts and resource requirements for LIBs.

Author Contributions: Conceptualization, A.N., R.A., S.P. and M.C.; methodology, A.N., R.A. and J.T.; formal analysis, A.N., R.A., M.C. and F.B.d.O.; Writing-original draft preparation, A.N., R.A. and S.P.; Writing-review and editing, A.N., R.A., M.C., F.B.d.O. and J.T.

Funding: This review was carried out as a joint effort involving participants funded in several different projects concerning batteries and LCA. The authors would like to express their gratitude for funding to the Swedish Electromobility Centre, the Swedish Energy Agency, the Swedish Research Council Formas and the Area of Advance Energy at Chalmers University of Technology.

Conflicts of Interest: The authors declare no conflict of interest. 


\section{References}

1. Whittingham, M.S. History, Evolution, and Future Status of Energy Storage. Proc. IEEE 2012, 100, $1518-1534$. [CrossRef]

2. Zubi, G.; Dufo-López, R.; Carvalho, M.; Pasaoglu, G. The lithium-ion battery: State of the art and future perspectives. Renew. Sustain. Energy Rev. 2018, 89, 292-308. [CrossRef]

3. Pehlken, A.; Albach, S.; Vogt, T. Is there a resource constraint related to lithium ion batteries in cars? Int. J. Life Cycle Assess. 2017, 22, 40-53. [CrossRef]

4. Oliveira, L.; Messagie, M.; Rangaraju, S.; Sanfelix, J.; Hernandez Rivas, M.; Van Mierlo, J. Key issues of lithium-ion batteries - from resource depletion to environmental performance indicators. J. Clean. Prod. 2015, 108, 354-362. [CrossRef]

5. Miedema, J.H.; Moll, H.C. Lithium availability in the EU27 for battery-driven vehicles: The impact of recycling and substitution on the confrontation between supply and demand until 2050. Resour. Policy 2013, 38, 204-211. [CrossRef]

6. Speirs, J.; Contestabile, M.; Houari, Y.; Gross, R. The future of lithium availability for electric vehicle batteries. Renew. Sustain. Energy Rev. 2014, 35, 183-193. [CrossRef]

7. Simon, B.; Ziemann, S.; Weil, M. Potential metal requirement of active materials in lithium-ion battery cells of electric vehicles and its impact on reserves: Focus on Europe. Resour. Conserv. Recycl. 2015, 104, 300-310. [CrossRef]

8. Kushnir, D.; Sandén, B.A. The time dimension and lithium resource constraints for electric vehicles. Resour. Policy 2012, 37, 93-103. [CrossRef]

9. Ellingsen, L.A.-W.; Hung, C.R.; Strømman, A.H. Identifying key assumptions and differences in life cycle assessment studies of lithium-ion traction batteries with focus on greenhouse gas emissions. Transp. Res. D Transp. Environ. 2017, 55, 82-90. [CrossRef]

10. Peters, J.F.; Weil, M. Providing a common base for life cycle assessments of Li-Ion batteries. J. Clean. Prod. 2018, 171, 704-713. [CrossRef]

11. Peters, J.F.; Baumann, M.; Zimmermann, B.; Braun, J.; Weil, M. The environmental impact of Li-Ion batteries and the role of key parameters-A review. Renew. Sustain. Energy Rev. 2017, 67, 491-506. [CrossRef]

12. Gaines, L.; Sullivan, J.; Burnham, A.; Belharouak, I. Life-Cycle Analysis of Production and Recycling of Lithium Ion Batteries. Transp. Res. Rec.: J. Transp. Res. Board 2011, 2252, 57-65. [CrossRef]

13. Gaines, L. To recycle, or not to recycle, that is the question: Insights from life-cycle analysis. MRS Bull. 2012, 37, 333-338. [CrossRef]

14. Zeng, X.; Li, J.; Singh, N. Recycling of Spent Lithium-Ion Battery: A Critical Review. Crit. Rev. Environ. Sci. Technol. 2014, 44, 1129-1165. [CrossRef]

15. Dewulf, J.; Van der Vorst, G.; Denturck, K.; Van Langenhove, H.; Ghyoot, W.; Tytgat, J.; Vandeputte, K. Recycling rechargeable lithium ion batteries: Critical analysis of natural resource savings. Resour. Conserv. Recycl. 2010, 54, 229-234. [CrossRef]

16. Nordelöf, A.; Messagie, M.; Tillman, A.-M.; Ljunggren Söderman, M.; Van Mierlo, J. Environmental impacts of hybrid, plug-in hybrid, and battery electric vehicles—what can we learn from life cycle assessment? Int. J. Life Cycle Assess. 2014, 19, 1866-1890. [CrossRef]

17. Kim, H.C.; Wallington, T.J.; Arsenault, R.; Bae, C.; Ahn, S.; Lee, J. Cradle-to-Gate Emissions from a Commercial Electric Vehicle Li-Ion Battery: A Comparative Analysis. Environ. Sci. Technol. 2016, 50, 7715-7722. [CrossRef]

18. Li, B.; Gao, X.; Li, J.; Yuan, C. Life Cycle Environmental Impact of High-Capacity Lithium Ion Battery with Silicon Nanowires Anode for Electric Vehicles. Environ. Sci. Technol. 2014, 48, 3047-3055. [CrossRef]

19. Sanfélix, J.; Messagie, M.; Omar, N.; Van Mierlo, J.; Hennige, V. Environmental performance of advanced hybrid energy storage systems for electric vehicle applications. Appl. Energy 2015, 137, 925-930. [CrossRef]

20. Ellingsen, L.A.-W.; Majeau-Bettez, G.; Singh, B.; Srivastava, A.K.; Valøen, L.O.; Strømman, A.H. Life Cycle Assessment of a Lithium-Ion Battery Vehicle Pack. J. Ind. Ecol. 2014, 18, 113-124. [CrossRef]

21. Dunn, J.B.; Gaines, L.; Sullivan, J.; Wang, M.Q. Impact of Recycling on Cradle-to-Gate Energy Consumption and Greenhouse Gas Emissions of Automotive Lithium-Ion Batteries. Environ. Sci. Technol. 2012, 46, 12704-12710. [CrossRef] [PubMed]

22. Saw, L.H.; Ye, Y.; Tay, A.A.O. Integration issues of lithium-ion battery into electric vehicles battery pack. J. Clean. Prod. 2016, 113, 1032-1045. [CrossRef] 
23. Kushnir, D. Lithium Ion Battery Recycling Technology 2015. In Current State and Future Prospects; ESAReport \# 2015:18; Chalmers University of Tehcnology: Gothenburg, Sweden, 2015.

24. Huisman, J.; Leroy, P.; Tertre, F.; Söderman, M.L.; Chancerel, P.; Cassard, D.; Løvik, A.N.; Wäge, P.; Kushnir, D.; Rotter, V.S. Prospecting Secondary Raw Materials in the Urban Mine and Mining Wastes (ProSUM)_Final Report. 21 December 2017: Brussels, Belgium. ISBN: 978-92-808-9061-7 (electronic). Available online: http://www.prosumproject.eu/sites/default/files/DIGITAL_Final_Report.pdf. (accessed on 28 March 2019).

25. Melin, H.E. Forskningsöversikt om återvinning och återbruk av litiumjonbatterier; Circular Energy Storage, Swedish Energy Agency: Eskilstuna, Sweden. Available online: http://www.energimyndigheten.se/ globalassets/forskning-innovation/overgripande/forskningsoversikt-om-atervinning-och-aterbruk-avlitiumjonbatterier-2019.pdf. (accessed on 29 March 2019).

26. Zheng, X.; Zhu, Z.; Lin, X.; Zhang, Y.; Hec, Y.; Cao, H.; Sun, Z. A Mini-Review on Metal Recycling from Spent Lithium Ion Batteries. Engineering 2018, 4, 361-370. [CrossRef]

27. Lv, W.; Wang, Z.; Cao, H.; Sun, Y.; Zhang, Y.; Sun, Z. A Critical Review and Analysis on the Recycling of Spent Lithium-Ion Batteries. ACS Sustain. Chem. Eng. 2018, 6, 1504-1521. [CrossRef]

28. Andersson, M.; Ljunggren Söderman, M.; Sandén, B.A. Are scarce metals in cars functionally recycled? Waste Manag. 2017, 60, 407-416. [CrossRef] [PubMed]

29. Gaines, L. The future of automotive lithium-ion battery recycling: Charting a sustainable course. Sustain. Mater. Technol. 2014, 1-2, 2-7. [CrossRef]

30. Ekberg, C.; Petranikova, M. Chapter 7-Lithium Batteries Recycling. In Lithium Process Chemistry; Chagnes, A., Światowska, J., Eds.; Elsevier: Amsterdam, The Netherlands, 2015; pp. 233-267.

31. Dunn, J.B.; Gaines, L.; Barnes, M.; Sullivan, J.; Wang, M. Material and Energy Flows in the Materials Production, Assembly, and End-of-Life Stages of the Automotive Lithium-Ion Battery Life Cycle. In Energy Systems Division, Argonne National Laboratory; ANL/ESD/12-3 Rev; U.S. Department of Energy: Argonne, IL, USA, 2014.

32. Ekvall, T.; Tillman, A.-M. Open-loop recycling: Criteria for allocation procedures. Int. J. Life Cycle Assess. 1997, 2, 155. [CrossRef]

33. Guérin, B.L.E. Modelling of Recycling in Life Cycle Assessment. Master's Thesis, Department of Environmental Engineering, Technical University of Denmark, Copenhagen, Denmark, 2017.

34. Atherton, J. Declaration by the Metals Industry on Recycling Principles. Int. J. Life Cycle Assess. 2007, 12, 59-60. [CrossRef]

35. Frischknecht, R. LCI modelling approaches applied on recycling of materials in view of environmental sustainability, risk perception and eco-efficiency. Int. J. Life Cycle Assess. 2010, 15, 666-671. [CrossRef]

36. Zackrisson, M.; Avellán, L.; Orlenius, J. Life cycle assessment of lithium-ion batteries for plug-in hybrid electric vehicles - Critical issues. J. Clean. Prod. 2010, 18, 1519-1529. [CrossRef]

37. Wernet, G.; Bauer, C.; Steubing, B.; Reinhard, J.; Moreno-Ruiz, E.; Weidema, B. The ecoinvent database version 3 (part I): overview and methodology. Int. J. Life Cycle Assess. 2016, 21, 1218-1230. [CrossRef]

38. ISO. Environmental Management_Life Cycle Assessment-Requirements and Guidelines; ISO 14044:2006; International Organization for Standardization: Geneva, Switzerland, 2016; p. 46.

39. Classen, M.; Althaus, H.-J.; Blaser, S.; Scharnhorst, W.; Tuchschmid, M.; Jungbluth, N.; Emmenegger, M.F. Life Cycle Inventories of Metals; Ecoinvent report No. 10. (Data v2.1); Swiss Centre for Life Cycle Inventories: Dübendorf, Switzerland, 2009.

40. Baumann, H.; Tillman, A.-M. The Hitch Hiker's Guide to LCA-An Orientation in Life Cycle Assessment Methodology and Application; Studentlitteratur: Lund, Sweden, 2004.

41. Finnveden, G.; Hauschild, M.Z.; Ekvall, T.; Guinée, J.; Heijungs, R.; Hellweg, S.; Koehler, A.; Pennington, D.; Suh, S. Recent developments in Life Cycle Assessment. J. Environ. Manag. 2009, 91, 1-21. [CrossRef] [PubMed]

42. Schrijvers, D.L.; Loubet, P.; Sonnemann, G. Critical review of guidelines against a systematic framework with regard to consistency on allocation procedures for recycling in LCA. Int. J. Life Cycle Assess. 2016, 21, 994-1008. [CrossRef]

43. Vadenbo, C.; Hellweg, S.; Astrup, T.F. Let's Be Clear(er) about Substitution: A Reporting Framework to Account for Product Displacement in Life Cycle Assessment. J. Ind. Ecol. 2017, 21, 1078-1089. [CrossRef]

44. Geyer, R.; Kuczenski, B.; Zink, T.; Henderson, A. Common Misconceptions about Recycling. J. Ind. Ecol. 2016, 20, 1010-1017. [CrossRef] 
45. Scopus. Online Subscription-Based Scientific Multi-Disciplinary Database 2019. Available online: https: //www.scopus.com (accessed on 27 February 2019).

46. Web of Science. Online Subscription-Based Aggregated Scientific Multi-Disciplinary Database. 2019. Available online: http://webofknowledge.com/WOS (accessed on 27 February 2019).

47. Wang, Y.; Yu, Y.; Huang, K.; Chen, B.; Deng, W.; Yao, Y. Quantifying the environmental impact of a Li-rich high-capacity cathode material in electric vehicles via life cycle assessment. Environ. Sci. Pollut. Res. 2017, 24, 1251-1260. [CrossRef] [PubMed]

48. Yu, Y.; Chen, B.; Huang, K.; Wang, X.; Wang, D. Environmental Impact Assessment and End-of-Life Treatment Policy Analysis for Li-Ion Batteries and Ni-MH Batteries. Int. J. Environ. Res. Public Health 2014, 11, 3185-3198. [CrossRef] [PubMed]

49. Casals, L.C.; García, B.A.; Aguesse, F.; Iturrondobeitia, A. Second life of electric vehicle batteries: relation between materials degradation and environmental impact. Int. J. Life Cycle Assess. 2017, 22, 82-93. [CrossRef]

50. Bobba, S.; Mathieux, F.; Ardente, F.; Blengini, G.A.; Cusenza, M.A.; Podias, A.; Pfrang, A. Life Cycle Assessment of repurposed electric vehicle batteries: An adapted method based on modelling energy flows. J. Energy Storage 2018, 19, 213-225. [CrossRef]

51. Argonne National Laboratory. GREET ${ }^{\circledR}$ Model-The Greenhouse Gases, Regulated Emissions, and Energy Use in Transportation Model. 2019. Available online: https://greet.es.anl.gov (accessed on 12 March 2019).

52. Sanfélix, J.; de la Rúa, C.; Schmidt, J.H.; Messagie, M.; Van Mierlo, J. Environmental and economic performance of an li-ion battery pack: A multiregional input-output approach. Energies 2016, 9, 584. [CrossRef]

53. Vandepaer, L.; Cloutier, J.; Bauer, C.; Amor, B. Integrating Batteries in the Future Swiss Electricity Supply System: A Consequential Environmental Assessment. J. Ind. Ecol. 2018, 23, 709-725. [CrossRef]

54. Ahmadi, L.; Young, S.B.; Fowler, M.; Fraser, R.A.; Achachlouei, M.A. A cascaded life cycle: reuse of electric vehicle lithium-ion battery packs in energy storage systems. Int. J. Life Cycle Assess. 2017, 22, 111-124. [CrossRef]

55. Ciez, R.E.; Whitacre, J.F. Examining different recycling processes for lithium-ion batteries. Nat. Sustain. 2019, 2, 148-156. [CrossRef]

56. Cusenza, M.A.; Bobba, S.; Ardente, F.; Cellura, M.; Di Persio, F. Energy and environmental assessment of a traction lithium-ion battery pack for plug-in hybrid electric vehicles. J. Clean. Prod. 2019, 215, 634-649. [CrossRef] [PubMed]

57. de Souza, L.L.P.; Lora, E.E.S.; Palacio, J.C.E.; Rocha, M.H.; Renó, M.L.G.; Venturini, O.J. Comparative environmental life cycle assessment of conventional vehicles with different fuel options, plug-in hybrid and electric vehicles for a sustainable transportation system in Brazil. J. Clean. Prod. 2018, 203, 444-468. [CrossRef]

58. Dunn, J.B.; Gaines, L.; Kelly, J.C.; James, C.; Gallagher, K.G. The significance of Li-ion batteries in electric vehicle life-cycle energy and emissions and recycling's role in its reduction. Energy Environ. Sci. 2015, 8, 158-168. [CrossRef]

59. Faria, R.; Marques, P.; Garcia, R.; Moura, P.; Freire, F.; Delgado, J.; de Almeida, A.T. Primary and secondary use of electric mobility batteries from a life cycle perspective. J. Power Sources 2014, 262, 169-177. [CrossRef]

60. Hendrickson, T.P.; Kavvada, O.; Shah, N.; Sathre, R.; Scown, C.D. Life-cycle implications and supply chain logistics of electric vehicle battery recycling in California. Environ. Res. Lett. 2015, 10, 014011. [CrossRef]

61. Notter, D.A.; Gauch, M.; Widmer, R.; Wäger, P.; Stamp, A.; Zah, R.; Althaus, H.-J. Contribution of Li-Ion Batteries to the Environmental Impact of Electric Vehicles. Environ. Sci. Technol. 2010, 44, 6550-6556. [CrossRef]

62. Oliveira, L.; Messagie, M.; Mertens, J.; Laget, H.; Coosemans, T.; Van Mierlo, J. Environmental performance of electricity storage systems for grid applications, a life cycle approach. Energy Convers. Manag. 2015, 101, 326-335. [CrossRef]

63. Raugei, M.; Winfield, P. Prospective LCA of the production and EoL recycling of a novel type of Li-ion battery for electric vehicles. J. Clean. Prod. 2019, 213, 926-932. [CrossRef]

64. Richa, K.; Babbitt, C.W.; Nenadic, N.G.; Gaustad, G. Environmental trade-offs across cascading lithium-ion battery life cycles. Int. J. Life Cycle Assess. 2017, 22, 66-81. [CrossRef]

65. Ryan, N.A.; Lin, Y.; Mitchell-Ward, N.; Mathieu, J.L.; Johnson, J.X. Use-Phase Drives Lithium-Ion Battery Life Cycle Environmental Impacts When Used for Frequency Regulation. Environ. Sci. Technol. 2018, 52, 10163-10174. [CrossRef] [PubMed] 
66. Swart, P.; Dewulf, J.; Biernaux, A. Resource demand for the production of different cathode materials for lithium ion batteries. J. Clean. Prod. 2014, 84, 391-399. [CrossRef]

67. Tagliaferri, C.; Evangelisti, S.; Acconcia, F.; Domenech, T.; Ekins, P.; Barletta, D.; Lettieri, P. Life cycle assessment of future electric and hybrid vehicles: A cradle-to-grave systems engineering approach. Chem. Eng. Res. Des. 2016, 112, 298-309. [CrossRef]

68. Unterreiner, L.; Jülch, V.; Reith, S. Recycling of Battery Technologies - Ecological Impact Analysis Using Life Cycle Assessment (LCA). Energy Procedia 2016, 99, 229-234. [CrossRef]

69. Vandepaer, L.; Cloutier, J.; Amor, B. Environmental impacts of Lithium Metal Polymer and Lithium-ion stationary batteries. Renew. Sustain. Energy Rev. 2017, 78, 46-60. [CrossRef]

70. Zhao, S.; You, F. Comparative Life-Cycle Assessment of Li-Ion Batteries through Process-Based and Integrated Hybrid Approaches. ACS Sustain. Chem. Eng. 2019, 7, 5082-5094. [CrossRef]

71. Richa, K.; Babbitt, C.W.; Nenadic, N.G.; Gaustad, G. Supplementary Material for Environmental Trade-Offs Across Cascading Lithium-Ion Battery Life Cycles; Golisano Institute for Sustainability, Rochester Institute of Technology: Rochester, NY, USA, 1 January 2017; p. 35. Available online: https://doi.org/10.1007/s11367-015-0942-3 (accessed on 12 March 2019).

72. European Union. Directive 2006/66/EC of the European Parliament and of the Council; Official Journal of the European Union: Luxembourg, 2006.

(C) 2019 by the authors. Licensee MDPI, Basel, Switzerland. This article is an open access article distributed under the terms and conditions of the Creative Commons Attribution (CC BY) license (http://creativecommons.org/licenses/by/4.0/). 